\title{
Overlap laser welding of 5052-H36 aluminum alloy: experimental investigation of process parameters and mechanical designs
}

\author{
Mohamad Idriss $^{1}$ (D) $\cdot$ Fatemeh Mirakhorli $^{1} \cdot$ Alain Desrochers $^{2} \cdot$ Ahmed Maslouhi $^{2}$
}

Received: 17 September 2021 / Accepted: 18 January 2022 / Published online: 27 January 2022

(c) Crown 2022

\begin{abstract}
In this study, the laser welding process is used to join 1.6-mm-thick AA5052-H36 sheets in an overlap joint configuration. Both pulse and oscillation laser beam welding were investigated for the first laser pass. Oscillation beam laser welding in continuouswave mode show more stable and sound weld with no porosity defects compare to pulse wave (PW) mode. The adopted welding power, speed, frequency, and defocus are $8 \mathrm{~kW}, 6.5 \mathrm{~m} / \mathrm{min}, 150 \mathrm{~Hz}$, and $+8 \mathrm{~mm}$, respectively. The obtained stitch welds are defects free (blowholes, micro-cracks, or porosities). A circular oscillation ramp-up/ramp-down PW mode is adopted for a second laser surface re-melting (LSR) pass. The corresponding welding power, speed, frequency, and defocus are $5 \mathrm{~kW}, 2.5 \mathrm{~m} / \mathrm{min}, 500 \mathrm{~Hz}$, and $+15 \mathrm{~mm}$, respectively. Shear tests are then performed to evaluate the mechanical properties of single lap joints (SLJ) for different stitch weld shapes, 2 gap tolerances $(0$ and $0.5 \mathrm{~mm})$, as well as with/without LSR pass. The best tests' reproducibility and highest dissipated energies ( $+42 \%$ when compared to the perpendicular direction) are obtained when the stitch weld direction corresponds to the loading direction. The second LSR pass provides more aesthetic joints with higher shear resistance $(\sim+1 \%$ to $+3 \%)$ due to a decrease in the weld surface underfill and undercut imperfections of the stitch weld. The part-to-part gap leads to higher shear resistance ( $+20 \%)$ owing to 2 main reasons: larger welding surfaces at the joint interface and higher hardness of the fusion zone. These findings are of great value for including laser welding technology in the automotive and surface transportation industries.
\end{abstract}

Keywords Laser welding $\cdot$ Oscillation beam $\cdot$ Aluminum alloy $\cdot$ Stitch weld shape $\cdot$ Gap bridging $\cdot$ Mechanical properties

\section{Introduction}

Over the past few decades, increasing demand for lightweight structures has led to an increase in the application of aluminum alloys (AA) in automotive industries [1]. The

\section{Highlights}

- Optimising process parameters led to laser-welded AA5052

joints free from any defect.

- No shielding gas and no filler materials were used, and no surface preparation was applied.

- Stitch-weld shape influences the reproducibility of shear tensile tests and absorbed energies.

- Second LSR pass leads to more aesthetic joints and better shear resistance.

- Gap leads to better resistance due to a free flow of the material and a more developed equiaxed region.

Mohamad Idriss

mohamad.idriss@cnrc-nrc.gc.ca

1 National Research Council Canada, Saguenay, QC G7H 8C3, Canada

2 Department of Mechanical Engineering, University of Sherbrooke, Sherbrooke, QC J1K 2R1, Canada outstanding properties of AA such as low density, good corrosion resistance, high specific strength, attractive appearance, and intrinsic recyclability explain their increasing demand in automotive industries [2]. With the extensive use of AA, increasing research studies are conducted to develop different joining techniques of this material. Baqer et al. [3] studied AA joining to $\mathrm{Ti}$ and $\mathrm{Mg}$ alloys. The main concern with this kind of dissimilar joining was the formation of brittle intermetallic compounds $\left(\mathrm{Al}_{3} \mathrm{Mg}_{2}, \mathrm{Ti}_{3} \mathrm{Al}, \mathrm{TiAl}\right)$. In another example, laser welding was coupled to adhesive bonding to achieve relatively resistant $\mathrm{Al}-\mathrm{Mg}$ hybrid joints [4].

In [5] and [6], an extensive study for joining $\mathrm{Al}$ alloys using laser welding was presented. The progressing application of laser welding technique for joining AA is mostly due to its unique characteristics such as high-power density that lead to a narrow fusion zone (FZ) and heat-affected zone (HAZ) [7], high penetration depth and production rate, low-stress concentration, and high weld accessibility for complex geometry [8]. Similar results were obtained by using an Nd:YAG laser welding source for joining magnesium alloy [9]. By choosing the right laser power, speed, 
and focal distance, Janasekaran et al. [10] succeeded to laser weld relatively resistant AA2024-O (3 mm) and AA7075-T6 $(2 \mathrm{~mm}) \mathrm{T}$-joints using a low power Yb-fiber laser without additions of filler materials.

However, laser welding of 5xxx Al alloys presents many challenges, especially the formation of pores in the weldment caused by the relatively low boiling temperature of magnesium element [11]. More specifically, in a recent numerical and experimental study, Beiranvand et al. [12] investigated the relation between $\mathrm{Mg}$ evaporation, laser absorption, and weld penetration in the case of PW of 3 different AA series (2xxx, 5xxx, and 6xxx). They proved that the weld penetration and profile as well as the laser power absorption are related to the $\mathrm{Mg}$ evaporation process rather than the $\mathrm{Mg}$ presence itself in the alloy.

Yuce et al. [13] studied the influence of laser power, welding speed, and focal point position on the tensile load, penetration depth, and weld seam width of specimens in the case of fiber laser lap welding of an AA5182. They showed that excessive heat input caused excessive penetration and evaporation of the weld bead which decreased the tensile load of the joints. They demonstrated experimentally that the focal point position influenced the weld width, as well as the penetration depth. 2-mm-thick AA5052 sheets were butt-jointed using a high-power $\mathrm{CO}_{2}$ laser in a continuous wave $(\mathrm{CW})$ welding mode [14]. Undercut, porosity, and crack were the main issues that were resolved by cleaning the base material, using shielding gas, and/or using filler metal. In [15], it was recommended to use shielding gas for laser welding of AA5xxx series in a manufacturing environment. Rapp et al. [16] recommended using a filler material for avoiding hot cracking and improving gap bridging.

However, more encouraging results were obtained on an AA6061-T6 with the use of a pulse wave (PW) laser welding mode [8] or an oscillation beam laser welding [17]. When compared to the $\mathrm{CW}$ welding mode, the PW laser beam reduces significantly the heat input for achieving the same penetration depth [18]. In [19] and [20], PW mode was used for reducing or eliminating solidification cracking and porosities in laser-welded AA. A ramp-up, ramp-down pulse shape with a reduction in laser power at the end of each pulse can reduce cracking in AA. The oscillatory welding pattern is a newly developed technique that is used for aluminum welding, mostly for gap-bridging and increasing the tolerance of the laser welding process. In [17] and [21], the oscillation pattern was adopted for controlling the melt pool morphology. It induces an elliptical weld pool instead of a teardrop and leads to a fine weld structure that withstands shrinkage load better and thus prevents crack initiation [22].

In addition to process parameters, the mechanical behavior of a laser-welded joint is also influenced by geometrical and manufacturing parameters such as part-to-part gap, second laser surface remelting (LSR) pass, and stitch weld shape. For a reliable welding joint, the authors in [23] recommended a part-to-part gap not exceeding $0.3 \mathrm{~mm}$ in overlap joint with an upper sheet thickness of $1.4 \mathrm{~mm}$. However, this value can hardly be respected in an industrial environment. As for the second LSR pass, it results in higher joint quality and better mechanical behavior for different types of materials $[24,25]$. However, the influence of the second LSR pass has not been studied yet in the case of laserwelding of 5xxx series Al alloys. Finally, Jeong et al. [26] studied different stitch weld shapes in the case of ultrahigh strength steel (UHSS) SLJ using laser-arc hybrid welding. All the studied stitch weld shapes were perpendicular to the loading direction. However, in welding design rules, it is recommended to weld in the direction of the applied load [27].

In this study, we investigate the feasibility of the laser welding process for joining 1.6-mm AA5052-H36 sheets in an overlap configuration. The assembly conditions simulate a real-world manufacturing environment where no prior surface cleaning and treatment are applied nor are shielding gas and filler materials used. From 8 different potential parameters' set, only one is adopted for the first welding pass based on the defects' presence in the weld seam. A total of 70 specimens are then prepared with 4 different stitch weld shapes and 2 different part-to-part gap values. Half of them undergo a second laser surface re-melting (LSR) pass to reduce the underfill and undercut imperfections of the weld surface. Finally, tensile shear tests, microhardness tests, microstructural analysis, SEM, and X-rays are all used for a thorough analysis and understanding of the prepared joints as well as their mechanical behaviors. The different steps of this experimental investigation are presented in Fig. 1.

\section{Materials and experimental tests}

\subsection{Materials and laser-welding procedure}

The studied material is a 1.6-mm-thick AA5052-H36. Dimensions and chemical composition of welded sheets are given in Table 1. Corresponding mechanical properties are given in Table 2.

For the laser-welded SLJs' preparation, a TRUMPF TRUDISK 10-kW solid-state disk laser with a wavelength of $1030 \mathrm{~nm}$ is used. The laser beam is then passed to SCANLAB's intelliWELD 30 FC galvanometer scanner through a $200-\mu \mathrm{m}$ fiber which gives a beam spot diameter of $0.85 \mathrm{~mm}$ at the focal spot. The scanner permits remote laser welding at a work distance of $460 \mathrm{~mm}( \pm 70)$. The samples were cleaned with acetone before welding, but no oxide removal was applied before welding, and no shielding gas was used during the welding process.

Different process parameter sets were investigated to obtain high-quality stitch welds. Several tests were done 


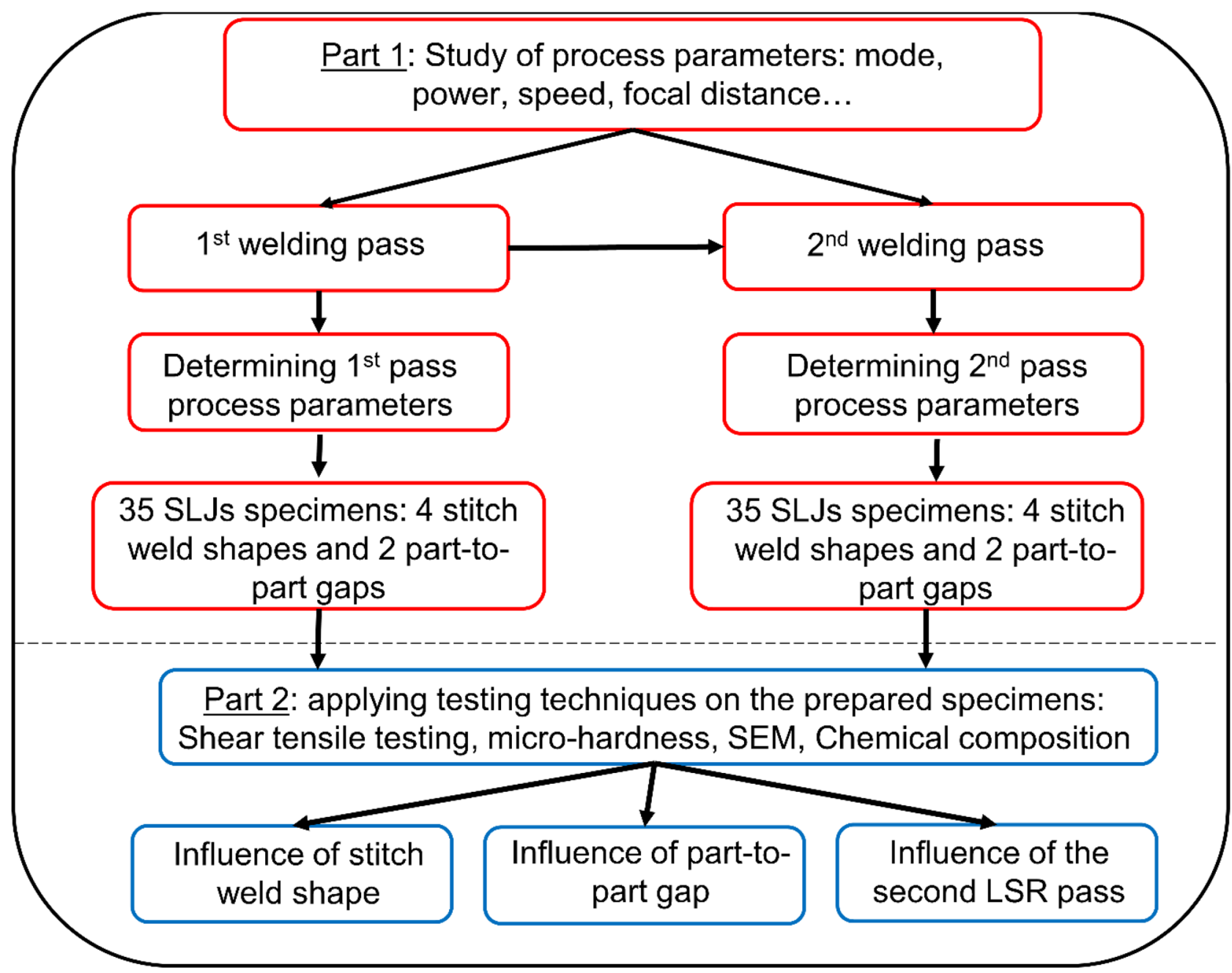

Fig. 1 Schematic representation of the overall study: part 1-determining process parameters of AA5052-H36 laser-welded SLJs; part 2mechanical and chemical behavior of the tested specimens

to determine a welding parameters' set leading to highperforming welding joints. Tables 3, 4 and 5 summarize all the process parameter sets investigated for the first welding pass and the second SLR pass. For the first welding pass, the laser beam was in CW and PW using oscillation beam patterns and linear non-oscillation patterns, respectively. Concerning the second LSR pass, CW and PW modes were investigated using laser oscillation patterns in both welding modes. Finally, the heat input values, calculated using Eq. (1), are presented in the last column of Table 3.

$Q_{L}=P_{L} /(60 * v)$ where $Q_{L}$ is the heat input $(\mathrm{J} / \mathrm{mm}), P_{L}$ is the laser power $(\mathrm{kW})$, and $v$ is the laser speed $(\mathrm{m} / \mathrm{min})$.

\subsection{Specimen preparation and mechanical testing}

After identifying the process parameter sets for both welding passes, 70 laser-welded SLJs were prepared. Table 6 summarizes the number of specimens prepared for each configuration (stitch weld shape, part-to-part gap, and second LSR pass). The effective weld stitch length was set to $30 \mathrm{~mm}$. Thus, the welding surface was approximately the same for all tested specimens.

Table 1 Chemical composition (weight \%) of the AA5052-H36

\begin{tabular}{|c|c|c|c|c|c|c|c|c|c|c|}
\hline Tested material & Dimensions $(\mathrm{mm})(\mathrm{L} * \mathrm{l} * \mathrm{e})$ & Al & Mg & $\mathrm{Cr}$ & $\mathbf{C u}$ & $\mathbf{F e}$ & Mn & $\mathbf{S i}$ & $\mathbf{Z n}$ & Autres \\
\hline -H36 & $150 * 75 * 1.6$ & 95.7-97.7 & $2.2-2.8$ & $0.15-0.35$ & $\leq 0.1$ & $\leq 0.4$ & $\leq 0.1$ & $\leq 0.25$ & $\leq 0.1$ & $\leq 0.15$ \\
\hline
\end{tabular}


Table 2 Mechanical properties of the AA5052-H36

\begin{tabular}{lllll}
\hline $\begin{array}{l}\text { Tested } \\
\text { material }\end{array}$ & \multicolumn{3}{l}{ Mechanical properties } & \\
\cline { 2 - 5 } & $\begin{array}{l}\text { Young's } \\
\text { modulus } \\
(\mathrm{MPa})\end{array}$ & $\begin{array}{l}\text { Yield strength } \\
\mathrm{R}_{02}(\mathrm{MPa})\end{array}$ & $\begin{array}{l}\text { Max. Tensile } \\
\text { strength } \\
(\mathrm{MPa})\end{array}$ & $\begin{array}{l}\text { Maximum } \\
\text { elongation } \\
(\%)\end{array}$ \\
\hline AA5052-H36 & 70000 & 230 & 297 & 7 \\
\hline
\end{tabular}

For detecting porosities, stitch welds were analyzed under X-ray, using a YXLON Y. Multiplex $5500 \mathrm{M}$ radiographic system, through the entire weld length.

One specimen per configuration was then cut perpendicularly to the welding direction. The obtained welding cross section was then grounded and polished with up to 600-grit $\mathrm{SiC}$ papers and finally mirror polished with $3-\mu \mathrm{m}$ diameter alumina particles.

Microhardness tests were then conducted on the prepared surfaces using a BUEHLER LTD. (Micromet II) microhardness machine. The tests were performed with a Vickers tungsten carbide indenter. The applied load was $200 \mathrm{~g}$ with a dwell time of $15 \mathrm{~s}$. Concerning the micrographic tests, the corresponding procedure is extensively explained in [8].

All the remaining specimens were then shear tensile tested until rupture by an MTS test frame 322 hydraulically controlled machine. The displacement speed was set at a constant value of $0.5 \mathrm{~mm} / \mathrm{min}$. The MTS data acquisition software recorded the applied forces $(\mathrm{N})$ and corresponding displacements ( $\mathrm{mm})$.

Finally, a scanning electron microscope (SEM; HITACHI, S-4700) equipped with a back-scattering electron detector and an energy dispersion X-ray spectrometry (EDS; Oxford instruments, X-MAX) was used for investigating the ruptured surfaces of the tested specimens and the chemical composition in the stitch weld. The accelerating voltage of electrons was set to $20 \mathrm{kV}$.
Table 4 Process parameter sets for the first welding pass in the case of the linear PW mode

\begin{tabular}{lllll}
\hline Trial & $\begin{array}{l}\text { Power } \\
(\mathrm{kW})\end{array}$ & $\begin{array}{l}\text { Speed } \\
(\mathrm{m} / \mathrm{min})\end{array}$ & Pulse shape & Defocus (mm) \\
\hline 1.8 & 8 & 6.5 & Ramp up - Ramp down & +18 \\
\hline
\end{tabular}

\section{Results}

\subsection{Welding process parameters}

\subsubsection{First welding pass}

Figure 2 presents the stitch weld surfaces corresponding to the process parameters' presented in Tables 3 and 4 . Blowhole(s) is the main defect observed, mostly during oscillation laser welding for oscillation amplitudes larger than $0.75 \mathrm{~mm}$. Increasing the welding speed to more than $7 \mathrm{~m} / \mathrm{min}$ at an oscillation amplitude of $0.75 \mathrm{~mm}$ also led to blowhole defects. Trials 1.4 (Oscillation pattern $\mathrm{CW}$ mode) and 1.8 (PW mode) show, visually, good results where no blowhole or undercut defects are detected in the weld surface. However, X-ray images (Fig. 3) show porosity formation during PW mode laser welding and no porosity formation during oscillation laser welding. Moreover, shear tensile testing shows better resistance of the oscillation pattern $\mathrm{CW}$ mode specimens (Fig. 4) where $r_{\text {max }}=\frac{\text { Maximum shear load }(k N)}{\text { stitch weld length }(m)}$ is represented for the 4 different configurations. Based on the obtained results, trial 1.4 process parameters' set is selected for the first welding pass. It is to note that the highest input heat value is obtained for this trial $(0.0205 \mathrm{~J} / \mathrm{mm})$. Although a high heat input leads to a wider FZ and HAZ [7], it has a positive effect of avoiding the formation of blowholes [28].

Table 3 Process parameter sets for the first welding pass in the case of the oscillation pattern CW mode

\begin{tabular}{|c|c|c|c|c|c|c|c|c|}
\hline \multirow[t]{2}{*}{ Trial } & \multirow[t]{2}{*}{ Power $(\mathrm{kW})$} & \multirow[t]{2}{*}{ Speed $(\mathrm{m} / \mathrm{min})$} & \multirow[t]{2}{*}{ Oscillation pattern } & $\mathbf{A M P 1}(\mathrm{mm})$ & AMP2 (mm) & \multirow[t]{2}{*}{$\begin{array}{l}\text { Frequency } \\
(\mathrm{Hz})\end{array}$} & \multirow[t]{2}{*}{$\begin{array}{l}\text { Defocus } \\
(\mathrm{mm})\end{array}$} & \multirow[t]{2}{*}{$\begin{array}{l}\text { Heat inpu } \\
(\mathrm{J} / \mathrm{mm})\end{array}$} \\
\hline & & & & Amplitude 1 & $\longrightarrow$ Ampilitude 2 & & & \\
\hline$\overline{1.1}$ & 7 & 7 & Transversal & 0 & 0.75 & 150 & +8 & 0.0167 \\
\hline 1.2 & 7.5 & 6.5 & Transversal & 0 & 0.75 & 150 & +8 & 0.0192 \\
\hline 1.3 & 7.5 & 7 & Transversal & 0 & 0.75 & 150 & +8 & 0.0179 \\
\hline 1.4 & 8 & 6.5 & Transversal & 0 & 0.75 & 150 & +8 & 0.0205 \\
\hline 1.5 & 8 & 6.5 & Transversal & 0 & 1 & 150 & +8 & 0.0205 \\
\hline 1.6 & 8 & 8 & Circle & 0.1 & 1 & 150 & +8 & 0.0167 \\
\hline 1.7 & 8 & 8 & Infinitive & 0.1 & 1 & 150 & +8 & 0.0167 \\
\hline
\end{tabular}


Table 5 Process parameter sets for the second LSR pass in the case of the oscillation pattern CW (trials 2.1 and 2.2) and PW (trial 2.3) modes

\begin{tabular}{lllllllll}
\hline Trial & Power $(\mathrm{kW})$ & Speed $(\mathrm{m} / \mathrm{min})$ & Oscillatory pattern & $\begin{array}{l}\text { AMP1 } \\
(\mathrm{mm})\end{array}$ & AMP2 $(\mathrm{mm})$ & $\begin{array}{l}\text { Frequency } \\
(\mathrm{Hz})\end{array}$ & Defocus $(\mathrm{mm})$ & Pulse shape \\
\hline 2.1 & 5 & 2.5 & Ellipse & 2.5 & 2 & 250 & +15 & NA \\
2.2 & 5 & 6.5 & Infinitive & 2.52 & 250 & +15 & NA \\
2.3 & 5 & 2.5 & Circle & 1.5 & 0 & 500 & +15 & Ramp up - Ramp down \\
\hline
\end{tabular}

\subsubsection{Second LSR pass}

The second LSR pass was applied to half of the welded specimens to increase the surface finish quality by removing the undercut and reducing the surface roughness and its influence on the mechanical behavior of the joint. Laser oscillation welding, in both $\mathrm{CW}$ and PW modes, was investigated after applying the second LSR pass (Fig. 5). Although a very smooth weld surface with no undercut defects was observed during visual inspection (Fig. 5), the LSR weld performed using oscillation beam in CW mode (trials 2.1 and 2.2) led to micro-cracks (Fig. 6a, b). Thus, oscillation beam welding in PW mode is selected for the second LSR pass, corresponding to trial 2.3, where no micro-cracks were observed.

\subsubsection{X-ray scanning}

In $\S 3.1 .1$ and 3.1.2, the parameters for preparing the first and second passes are determined. For the first welding pass, these parameters yielded laser welds without porosity or micro-crack defects. The second LSR pass smoothened the welding surfaces' undercut or underfill formed during the first pass. These parameters were used for preparing all the specimens for further microstructure and mechanical properties (presented in §2) and are studied in $\$ 3.2$. X-ray scanning confirmed that all prepared stitch welds were free from any blowhole, solidification cracking, or porosities (Fig. 7).

\subsection{Mechanical testing}

\subsubsection{Microstructure, micro-hardness, and chemical composition}

As mentioned in $\$ 2.2$, before conducting destructive testing, one specimen per configuration was sacrificed for microstructural analysis, micro-hardness tests, and chemical composition analysis. Thus, more information was obtained for understanding the influence of the stitch weld shape, part-topart gap, and second LSR pass on the mechanical behavior of the prepared welded joints.

Table 6 Number of welded specimens prepared for each configuration: each tested configuration has a different stitch weld shape and/or part-topart gap and/or number of welding passes

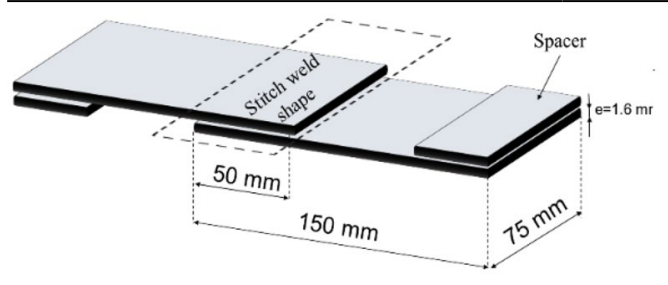

Laser weld

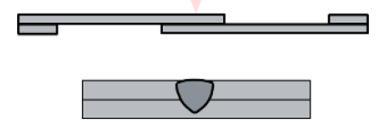

Gap05

Laser weld
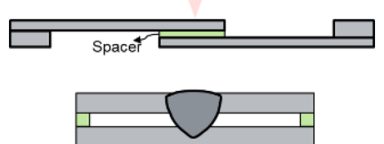

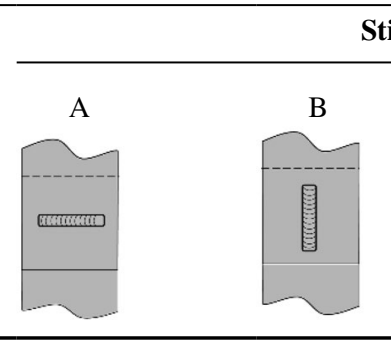

5

1 pass

Stitch weld shape

(2)

5

2 passes

5

5

5

I

1 pass

5

5

5

5

2 passes

5

5

5

5 


\begin{tabular}{|c|c|c|c|c|c|}
\hline Trial & $\begin{array}{c}\text { Obtained laser } \\
\text { welds }\end{array}$ & Defects & Trial & $\begin{array}{c}\text { Obtained laser } \\
\text { welds }\end{array}$ & Defects \\
\hline 1.1 & 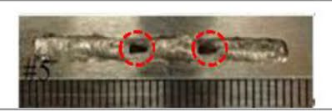 & Blowholes & 1.5 & \#2 & $\begin{array}{c}\text { Blowhole } \\
\text { channel }\end{array}$ \\
\hline 1.2 & iil & Undercut & 1.6 & 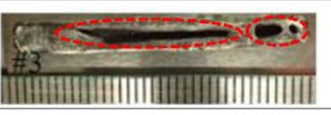 & $\begin{array}{l}\text { Blowhole } \\
\text { channel }\end{array}$ \\
\hline 1.3 & 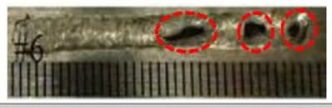 & Blowholes & 1.7 & 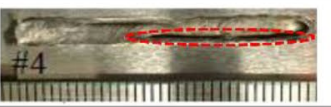 & $\begin{array}{c}\text { Blowhole } \\
\text { channel }\end{array}$ \\
\hline 1.4 & $\begin{array}{ll} \\
\text { \#1 } \\
1\end{array}$ & Good & 1.8 & 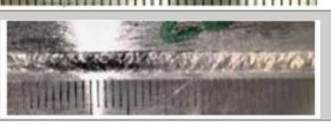 & Good \\
\hline
\end{tabular}

: Presence of blowhole defects

Fig. 2 Obtained stitch welds for all process parameter sets investigated in the case of the first welding pass

Figure 8 summarizes the cross-sectional microstructures of the welds for both part-to-part gaps and both welding passes. The second LSR pass affects the top surface of the joint leading to a more aesthetic joint and a decrease in its top surface concavity or underfill. As for the part-to-part gap, it leads to a more important underfill imperfection, but wider weld surfaces are obtained at the weld interface. Finally, with sheets in contact (Gap00), the microstructure is mainly dendritic with a limited equiaxed region in the top center of the FZ. As for the Gap05 case, a limited dendritic region is formed in favor of an important equiaxed region in the center of the FZ.

Figure 9 shows the microhardness profiles obtained in the middle thickness of the upper welded sheet for different configurations investigated. For both gap values, the hardness in the FZ is lower than the BM hardness. Also, for all the tested configurations, the hardness values of the FZ and HAZ, in the Gap05 case, are higher than the corresponding hardness in the Gap00 case. In each figure, the dashed and continuous horizontal segments correspond to the mean hardness value in the FZ for the Gap05 and Gap00 cases, respectively. Depending on the tested configuration, the observed increase in $\mathrm{HV}$ values is between 3 and $15 \%$.

Finally, the chemical composition investigation shows the evaporation of the $\mathrm{Mg}$ element in the FZ for both gap values (Fig. 10).

\subsubsection{Tensile testing and SEM}

All the remaining specimens are shear tensile tested (Table 6 and Appendix A-Fig. 15). Ratio $r=\frac{\text { Shear load }(k N)}{\text { Stitch weld length }(m)}$ to displace-
Fig. 3 X-ray images of laser welds in the oscillation pattern CW mode and linear PW mode

\section{Oscillation pattern CW mode Linear PW mode}

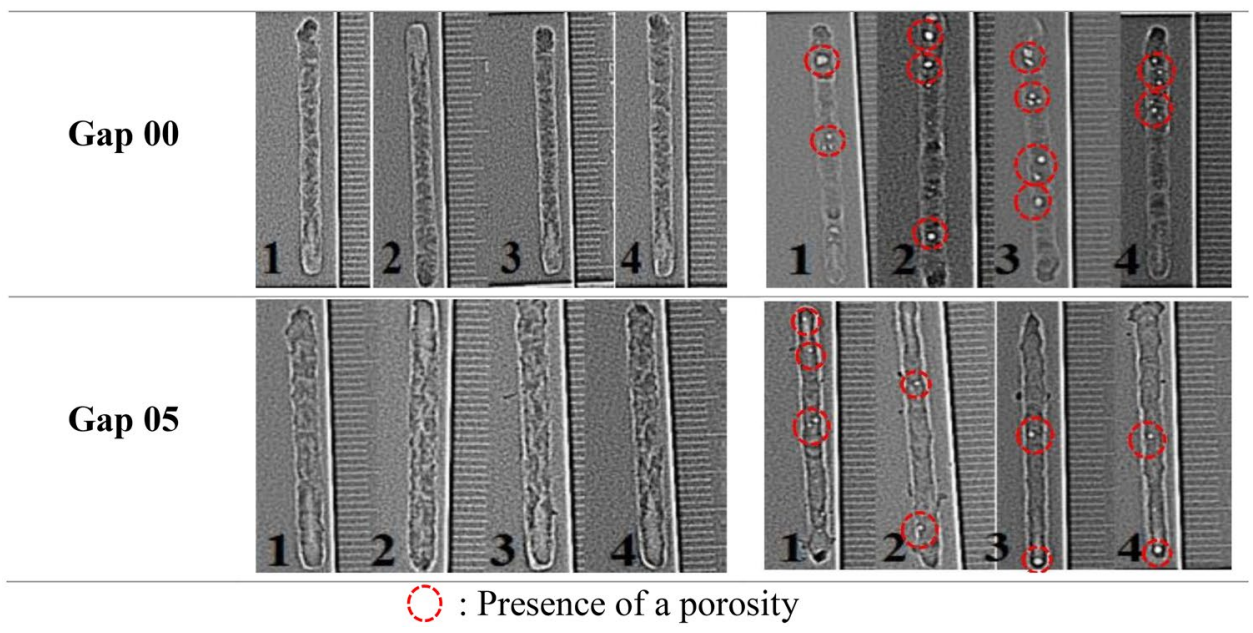




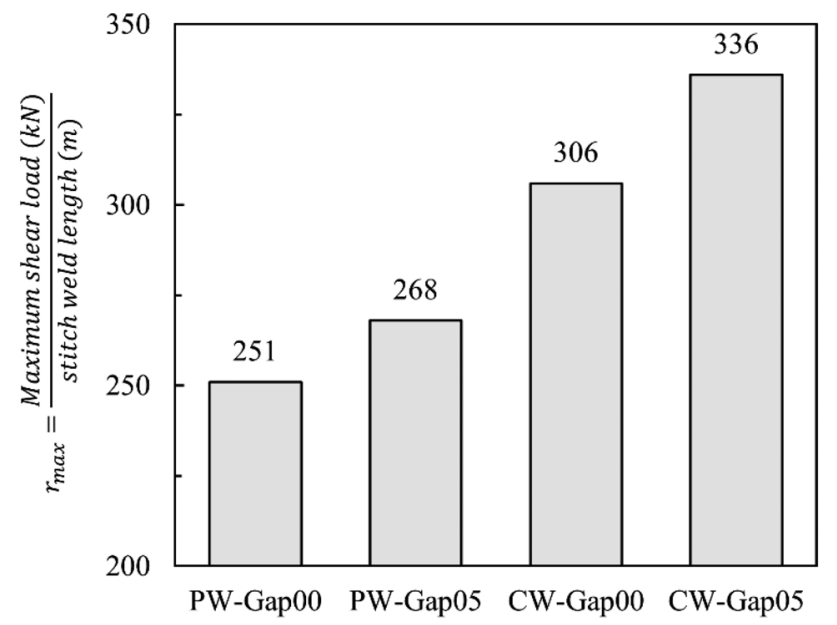

Fig. 4 Maximum shear load to welding length ratio $(\mathrm{kN} / \mathrm{m})$ obtained in the oscillation CW mode and PW mode

ment $(\mathrm{mm})$ curves are presented in Appendix A-Fig. 15. $r_{\max }$ defined in $\S 3.1 .1$ as well as the corresponding standard deviation for each tested configuration are presented in Fig. 11:

- There is no clear influence of the stitch weld shape on the maximum shear load. However, the reproducibility of the tests increases (standard deviations decrease) in the following order: Stitch weld $\mathrm{A}=>\mathrm{E}=>\mathrm{D}=>\mathrm{B}$.

- For all the tested cases, the second pass leads to a higher shear resistance of the joint. For the Gap05 case, the second pass leads to better reproducibility (lower standard deviations).

- For all the tested cases, the part-to-part gap leads to an important increase in the shear resistance of the joint.

Figure 12 a represents the total dissipated energy to achieve the total rupture of the tested specimens. Each bar of the graph is split into two numbers representing the percentages of dissipated energies before crack initiation (number below) and after crack initiation, up until total rupture (number above) (Fig. 12b). The stitch weld shape influences the total dissipated energies. Total dissipated energies increase in the following order: stitch weld $\mathrm{A}=>\mathrm{E}=>\mathrm{D}=>\mathrm{B}$. Moreover, the stitch weld shape influences the dissipated energies before and after crack initiation. Stitch weld B is the most resistant between the phase of crack initiation and total rupture. The part-to-part gap leads to an important increase in the total dissipated energy. However, the part-to-part gap leads to a decrease in the $\%$ of dissipated energies after crack initiation. The second LSR pass doesn't seem to have any influence on the dissipated energies.

The obtained rupture surfaces after shear tensile testing are observed with SEM. The SEM images for the rupture surfaces of all the stitch weld shapes are presented in Fig. 13. In the case of stitch weld A (horizontal weld), the rupture is mainly unstable (fragile: smooth surface) while for stitch weld B (vertical weld), the rupture is mainly stable (ductile: half-cavities surface). A mixedmode (I and II) controls the rupture occurrence in stitch welds D and E. For stitch weld E, the rupture propagation is unstable in the horizontal regions, similar to stitch weld A, and then stabilizes, similar to stitch weld B, in the vertical region.

\section{Discussion}

\subsection{Welding process parameters}

In oscillation laser welding, the higher the amplitude, the larger the melt pool is. This disturbs the balance between surface tensional pressure and recoil pressure around the keyhole that remains as a hole after the solidification of the
Fig. 5 Visual inspection of the obtained surfaces after the LSR pass

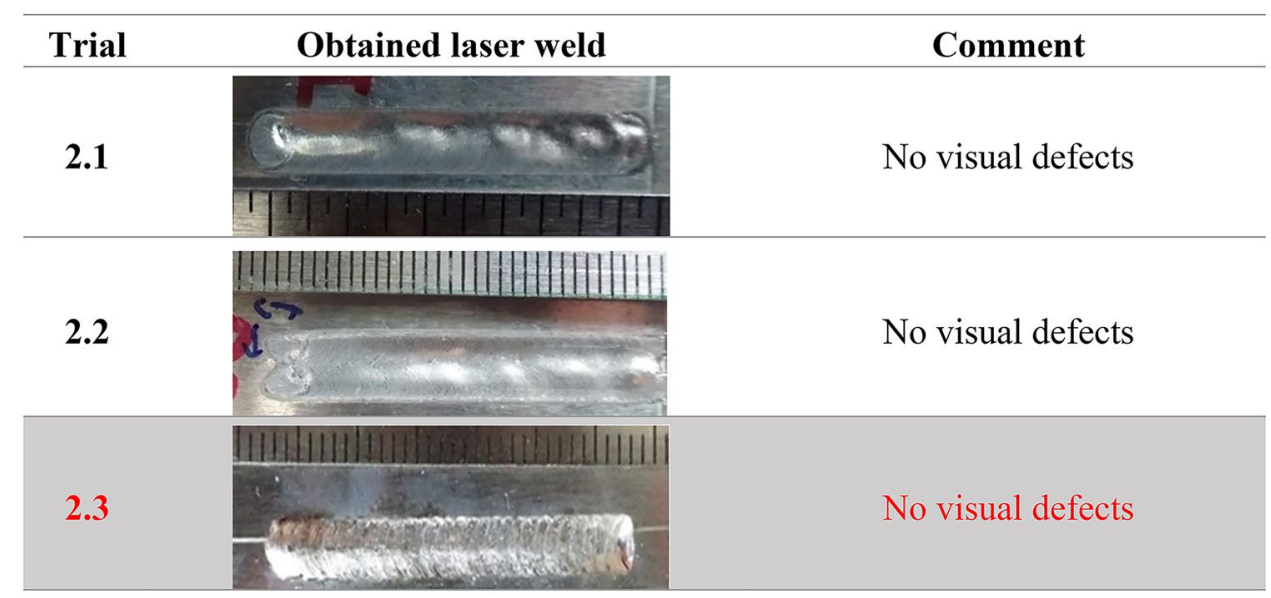


Fig. 6 Microstructure for each trial related to the second LSR pass

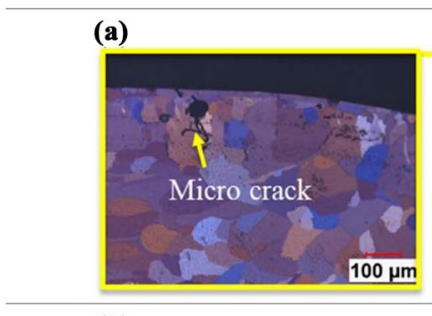

(b)

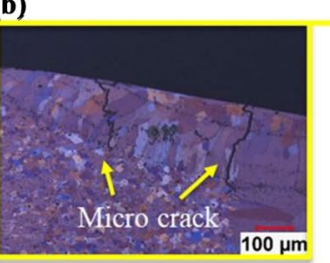

(c)

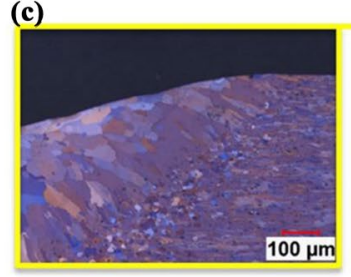

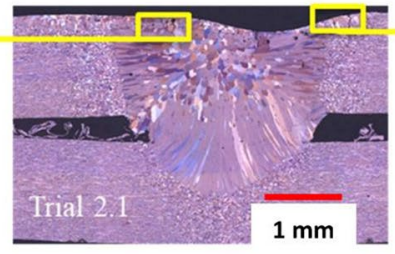
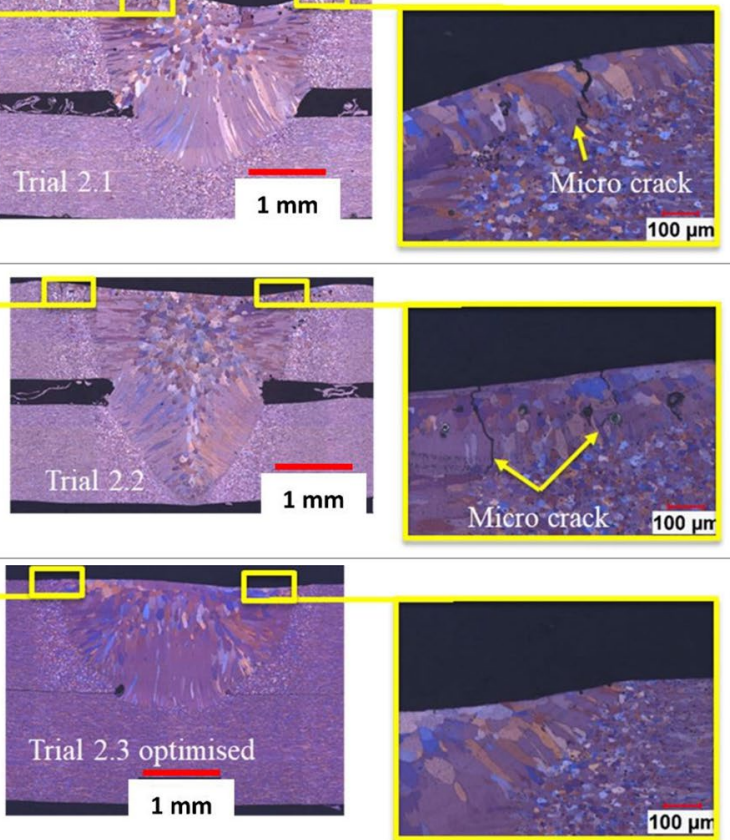

fusion zone. Increasing laser welding speed causes more susceptibility to solidification cracking, though higher speeds (lower heat input) result in finer dendrite structure and grain size as explained by [29]. Therefore, in this study, the best welding quality is obtained for the lowest welding speed of $6.5 \mathrm{~m} / \mathrm{min}$ and half amplitude of $0.75 \mathrm{~mm}$. Also, oscillatory mode reduces welding porosity. It establishes a relatively steady keyhole and improves the weld

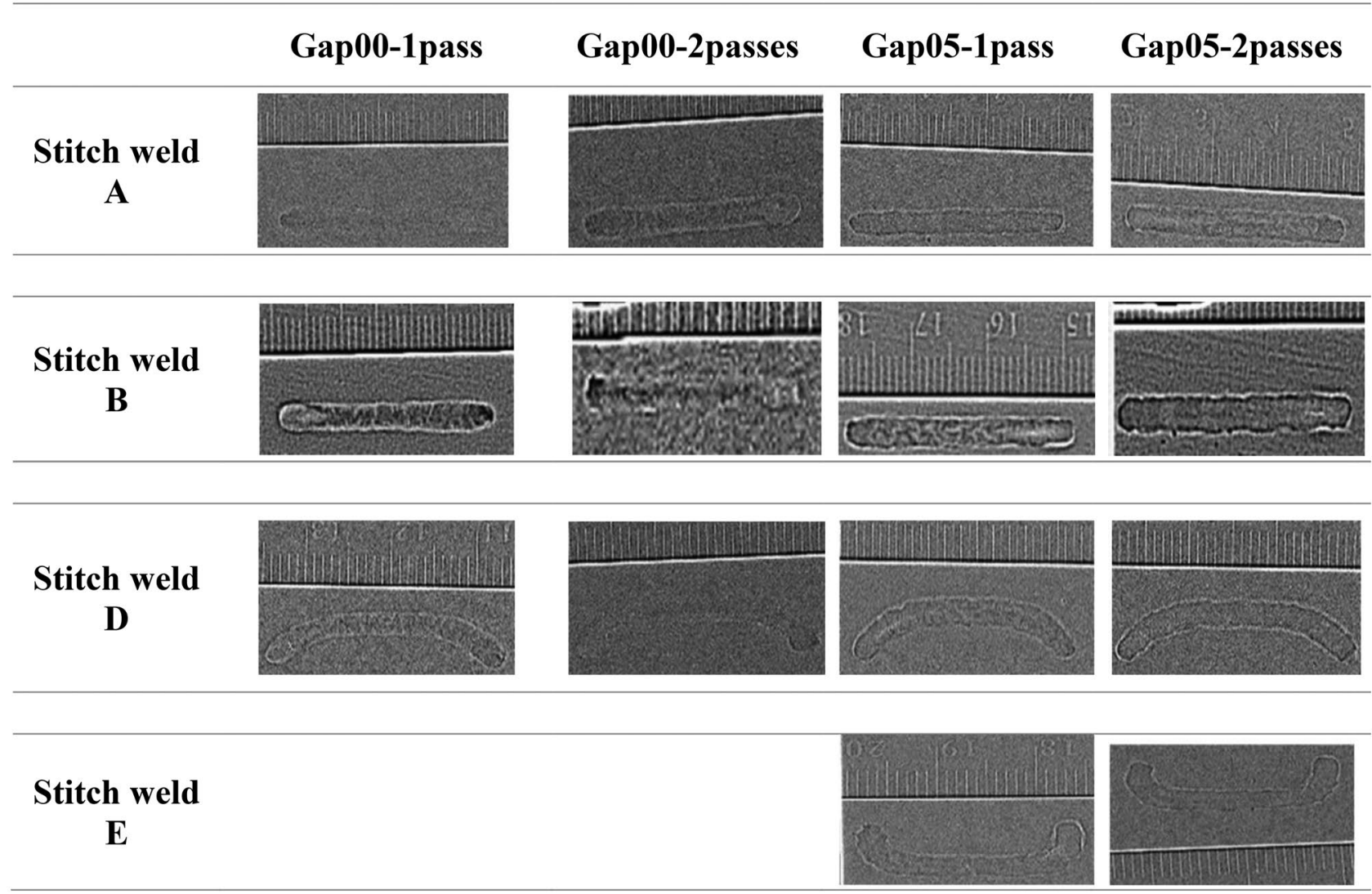

Fig. 7 X-ray photographs for some prepared stitch welds 
Fig. 8 Cross-sectional microstructures for both part-to-part gaps and both laser passes

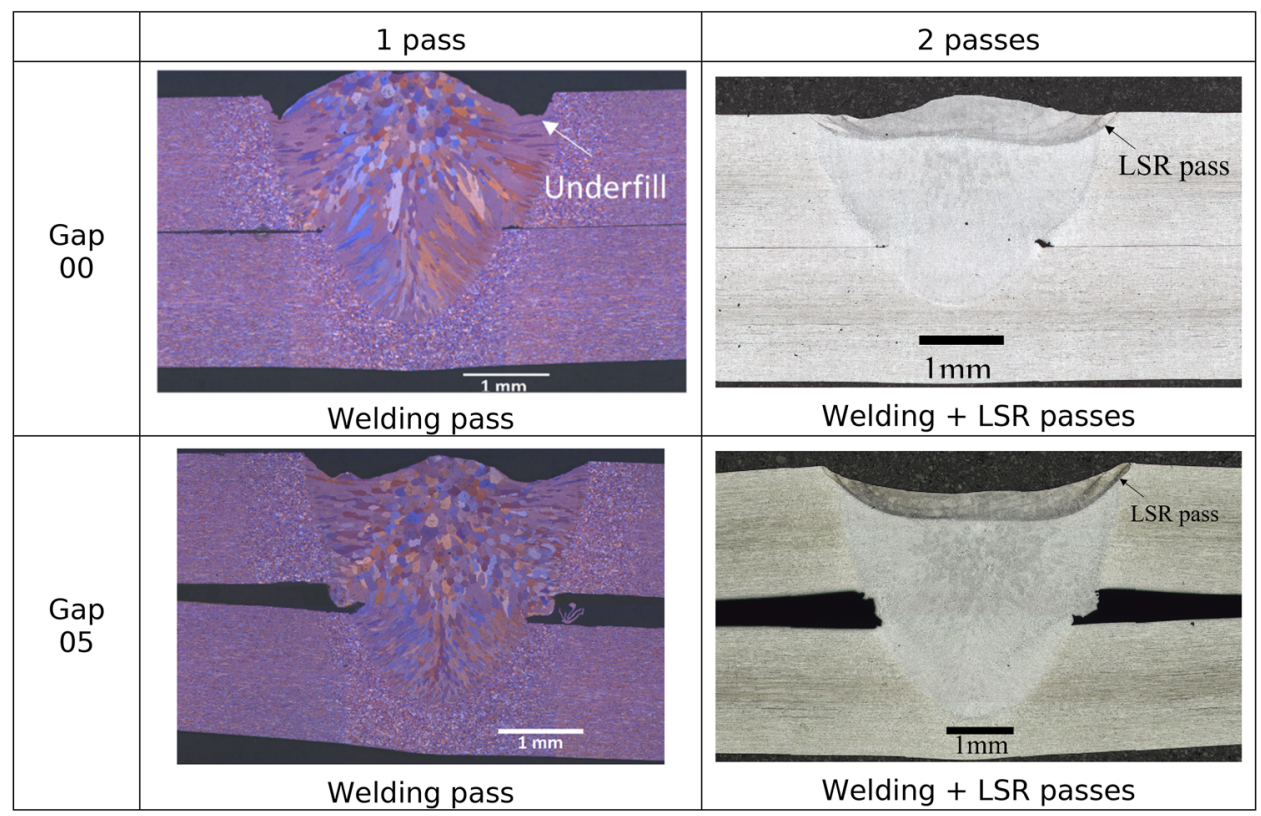

microstructure which, in turn, reduces the probability of defect formation [22].

In PW mode, the porosity formation is mostly due to keyhole instability. This is attributed to the increased potential for gas to escape during the delayed solidification time for low laser welding speeds.

The second LSR pass led to stitch welds without any visual defect (Blowhole, undercut). In CW mode, micro-cracking is

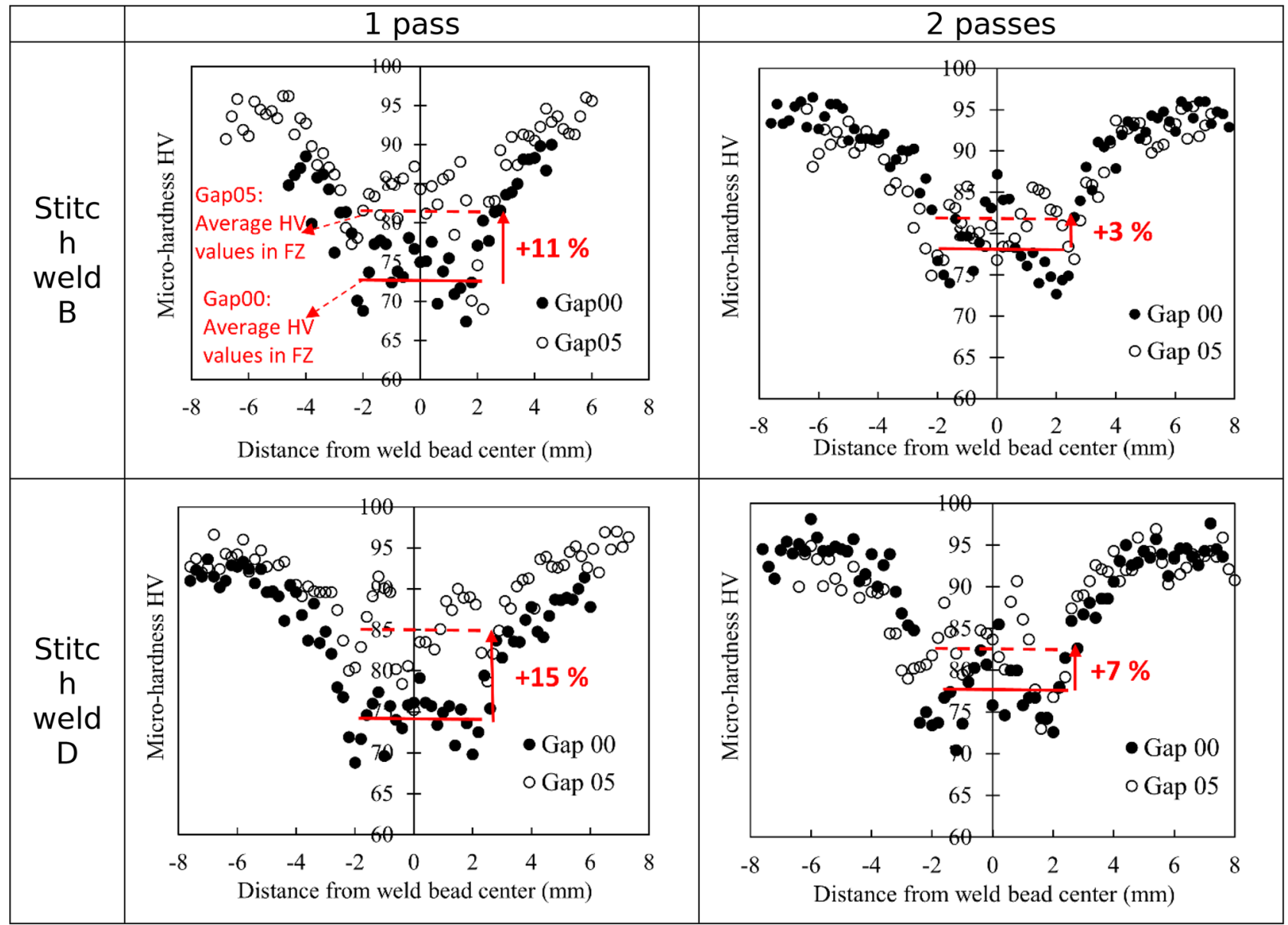

Fig. 9 Microhardness profiles obtained for different configurations 


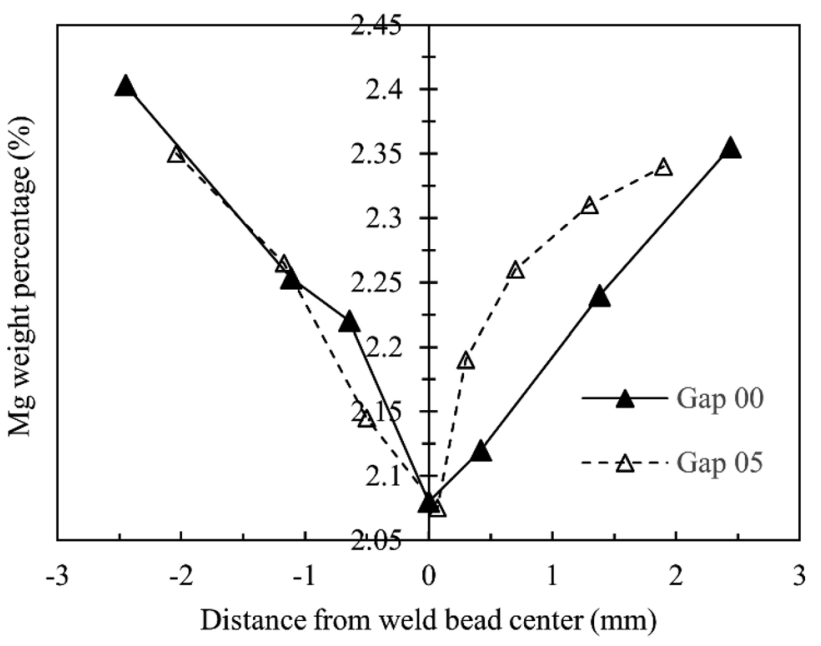

Fig. 10 Weight percentage of $\mathrm{Mg}$ element in the FZ in both cases: Gap00 and Gap05

related to the decrease in $\mathrm{Mg}$ content which increases crack sensitivity [30]. However, PW mode superimposed on oscillation beam welding leads to the elimination of micro-crack during LSR pass. It has been reported that PW mode laser welding controls the energy flow into the material and thereby controls the solidified microstructure, porosity, and solidification cracking $[5,6]$.

\subsection{Stitch weld shape}

Stitch weld shape doesn't influence the ratio $r_{\text {max }}$ but influences the reproducibility of the tests (Fig. 11). Moreover, it influences the total dissipated energies as well as the dissipated energies before and after crack initiation (Fig. 12). The total dissipated energy and the ratio of

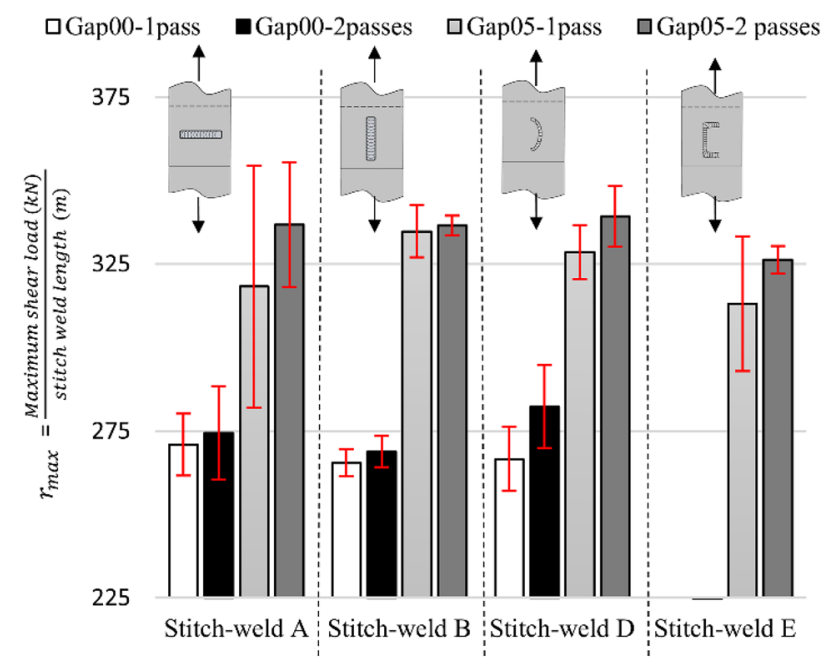

Fig. $11 r_{\max }=\frac{\text { Maximum shear load }(\mathrm{kN})}{\text { stitch weld length }(\mathrm{m})}(\mathrm{kN} / \mathrm{m})$ and its corresponding standard deviation for each tested configuration dissipated energy after crack initiation to total dissipated energy are the highest for stitch weld $\mathrm{B}$. This is related to the welding direction when compared to the load direction.

In a laser-welded SLJ, the stress field in the joint is much more complex than the nominal stress in each sheet corresponding to the ratio between the applied load and the nominal sheet area. One of the most influencing loads is the bending load leading to an opening in the sheet tips (Fig. 14c-e). This load type leads to an unstable rupture mode (mode I). For stitch weld A (perpendicular stitch weld direction to load direction), the opening in the sheet tips is much more important than the one in the case of stitch weld B (Fig. 14c, d). This explains the relatively low and high dissipated energies in the case of stitch welds A and B, respectively, when compared to other stitch welds E and D (Fig. 12).

Moreover, in the case of stitch weld A, after crack initiation, the crack propagates in the width $(4 \mathrm{~mm})$ of the weld seam, whereas for stitch weld $B$, the crack propagates along the length of the weld seam $(30 \mathrm{~mm})$. This explains why the dissipated energy after crack propagation is the lowest in the case of stitch weld A and the highest for stitch weld B (Fig. 12a). Stitch welds D and E are a combination of stitch welds A and B. This explains their similar mechanical behavior and the corresponding $r, r_{\text {max }}$, and dissipated energy values situated in between the ones corresponding to stitch welds A and B, respectively.

These results validate a general welding design rule that recommends orienting the weld seam in the direction of the applied load. Moreover, these findings help to anticipate a similar mechanical behavior of these stitch weld shapes under fatigue testing.

\subsection{Second LSR pass}

The second pass leads to more aesthetic joints with a decrease in the underfill at the top surface of the joint (Fig. 8). Thus, a better weld pool quality is obtained leading to a higher shear tensile strength (Fig. 11) [23]. Nevertheless, the second LSR pass leads to an improvement in the weld quality in the FZ/HAZ interface (Fig. 8) but doesn't influence the weld defects all along the joint interface. Thus, the second LSR pass improves the welding resistance in stitch weld $A$ (where the rupture occurs in the FZ/HAZ interface and is initiated at the top surface) more significantly than stitch weld B (where rupture occurs in the stitch weld interface section in-between the sheets) (Fig. 11).

\subsection{Part-to-part gap (gap-bridging)}

$r_{\text {max }}$ and the total dissipated energies of the welded joints increase significantly with the part-to-part gap (Figs. 11 and 12). This is due to 2 main reasons: 
(a)

口Gap00 - 1pass -Gap00 - 2passes 口Gap05- 1pass aGap05 - 2passes

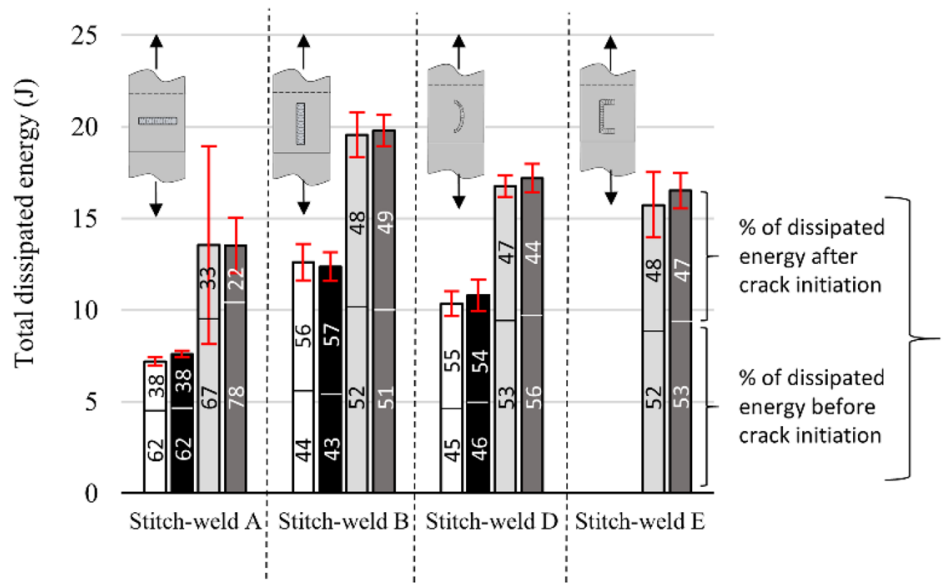

(b)

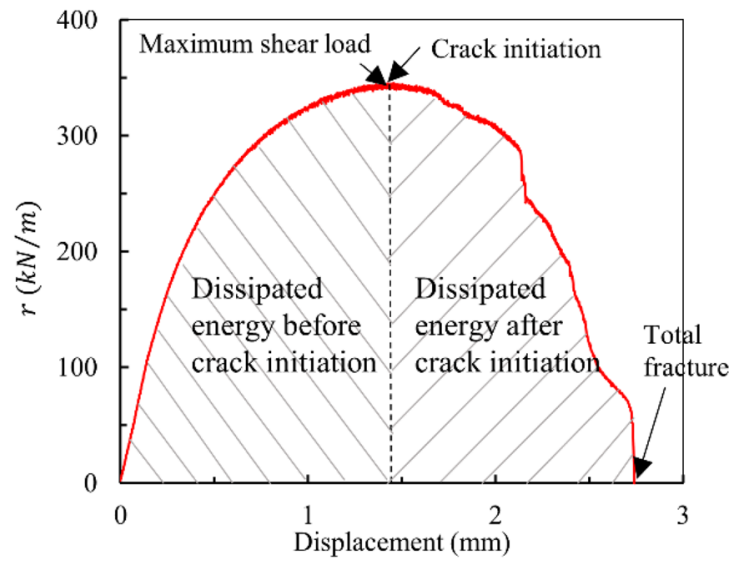

Fig. 12 a Total dissipated energy (J) and corresponding standard deviation for each tested configuration; each bar is split into lower and upper parts representing the $\%$ of dissipated energies before and after crack initiation, respectively. b Schematic representation of the dissipated energies before and after crack initiation
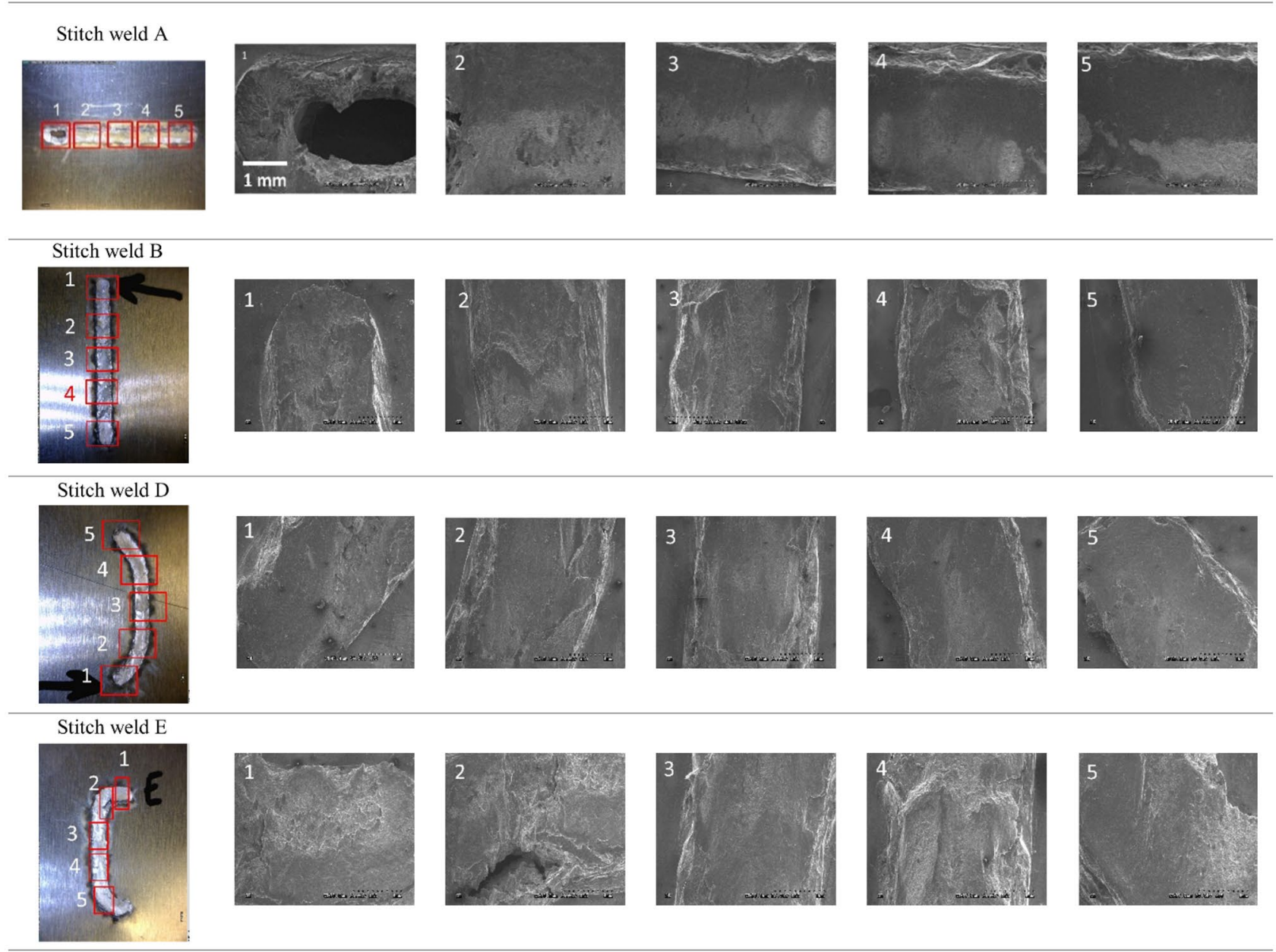

Fig. 13 SEM photos extracted from 5 different zones of the weld rupture surface for all stitch weld shapes. The scale represented in Fig. 1 of stitch weld $\mathrm{A}$ is the same for all the remaining figures 
Fig. 14 Influence of the direction of the stitch weld shape compared to the load direction: a front view of stitch welds A and B. b Side view of stitch welds. c Side view of real SLJ specimens during shear tensile testing at instant " $\mathrm{t}$ " before total rupture. d Gap variation between upper and lower sheets due to resulting bending loads. e Schematic representation of the gap variation and transversal load variation in the lap joint. f Schematic representation of rupture modes in stitch welds

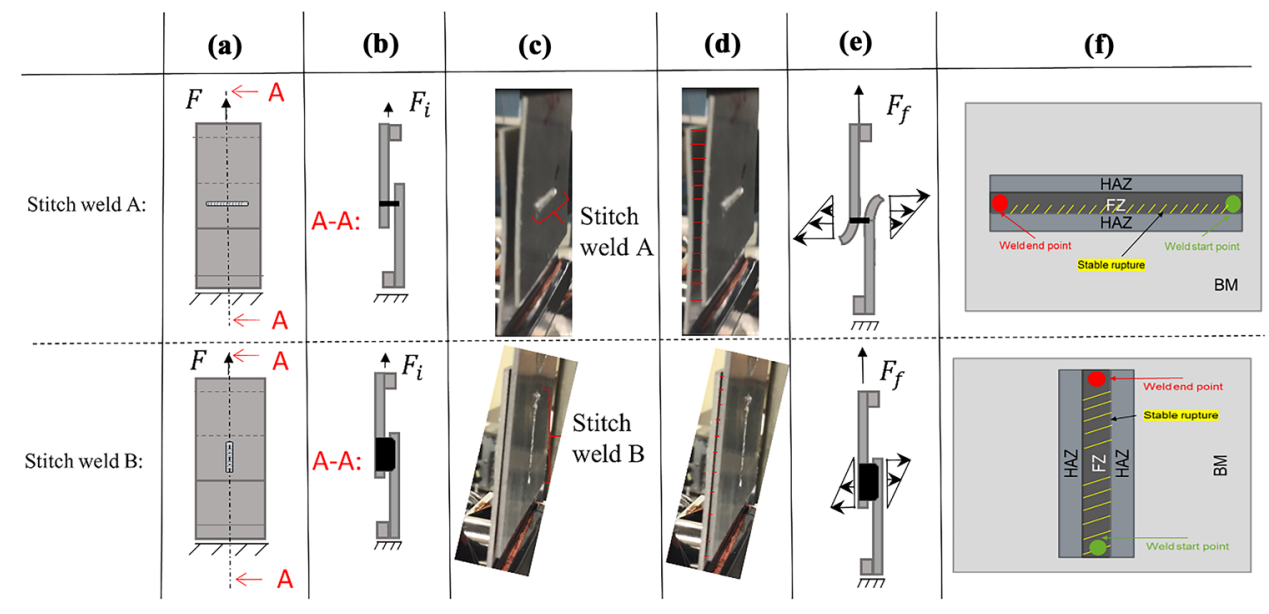

When the gap exists, the material is free to flow in between the welded sheets during welding. This leads to wider weld surfaces between AA sheets which, in turn, leads to higher resistance before rupture. The second reason is deduced from the microhardness profiles obtained in the middle-thickness of the upper welded sheet. For Gap05, the mean hardness value of the FZ and HAZ is higher (3\% to $15 \%$ depending on the tested configuration) than the corresponding hardness in the Gap00 case (Fig. 9). The microstructure investigations show that for the Gap00 case, the microstructure of the FZ and HAZ is mainly dendritic. A limited equiaxed region appears in the top center of the FZ. However, for Gap05, the FZ consists mainly of equiaxed grains limited by a dendritic structure. The difference in the equiaxed region dimensions is mainly due to the cooling rate. In the Gap00 case, the lower sheet is in contact with the upper one. The large contact surface between both sheets accelerates the cooling of the upper one and leads to an important dendritic region. In the Gap05 case, the welded sheets are not in contact. The only thermal bridge between both sheets is the stitch weld. This decreases the cooling rate of the upper sheet, leading to an important equiaxed region [31, 32].

Finally, for both cases (Gap00 and Gap05), the hardness in the FZ is lower than the BM hardness. The base material is initially work-hardened (H36: $3 / 4$ stable hardening). The welding process leads to a degradation in the mechanical properties of the FZ-HAZ region, and the solidified material is no more in the H36 condition [14]. The lower hardness values are also due to the evaporation of the $\mathrm{Mg}$ volatile element [33] as shown in Fig. 10. The Mg element is harder than the $\mathrm{Al}$ element, and its evaporation creates voids in the weld region which leads to a decrease in the microhardness values of the FZ and HAZ.

\section{Conclusions}

In this work, 1.6-mm-thick AA5052-H36 sheets were successfully laser welded without any filler material, protection gas, or pre-preparation of the welded surface using the oscillation beam laser technique. The following results are concluded:

1. Two welding passes were used to achieve sound welds with no porosity and underfill or undercut defects. For the first welding pass, transversal oscillation beam ( $0.75 \mathrm{~mm}$ half amplitude and $150 \mathrm{HZ}$ frequency) laser welding with the welding parameters' set of $8 \mathrm{~kW}$, $6.5 \mathrm{~m} / \mathrm{min}, 150 \mathrm{~Hz},+8 \mathrm{~mm}$ defocus was used. To achieve a more aesthetic weld surface, a second laser surface re-melting (LSR) pass was applied using a circular oscillation beam (1.5-mm half amplitude and 500-Hz frequency) laser impulse mode with ramp-up/ ramp-down pulse shape and the following parameters' set $(5 \mathrm{~kW}, 2.5 \mathrm{~m} / \mathrm{min}, 500 \mathrm{~Hz},+15 \mathrm{~mm}$ defocus) which led to stitch welds free from visual surface geometrical defects as well as micro-cracks. The second LSR pass increased slightly the shear resistance of the joint $(\sim+1 \%$ to $+3 \%)$ due to more aesthetic joints where underfill is reduced.

2. The stitch weld shape influenced the reproducibility of the tests and the dissipated energy values. For stitch weld B (aligned weld and loading direction), the standard deviation values varied between $2.9583 \mathrm{kN} / \mathrm{m}$ and $7.833 \mathrm{kN} / \mathrm{m}$, and the energy values varied from 12.366 to $19.62 \mathrm{~J}$. For stitch weld A (perpendicular weld and loading direction), the standard deviation values varied between $9.32 \mathrm{kN} / \mathrm{m}$ and $36.13 \mathrm{kN} / \mathrm{m}$, and the energy values varied from $7.2 \mathrm{~J}$ to $13.54 \mathrm{~J}$. This is a $215 \%$ to $360 \%$ increase in the standard deviation values and a 45 to $72 \%$ decrease in the energy values. 
3. The part-to-part gap led to higher shear resistance $(\sim+20 \%)$. The gap allowed the melted material to flow freely between the sheets. This created a wider weld at the joint interface and induced higher shear resistance. Also, the microhardness profiles showed higher resistance $(+3$ to $+15 \%)$ in the case of the part-to-part gap due to a more developed equiaxed microstructure in the FZ related to a lower cooling rate.

(a) Gap00-1pass
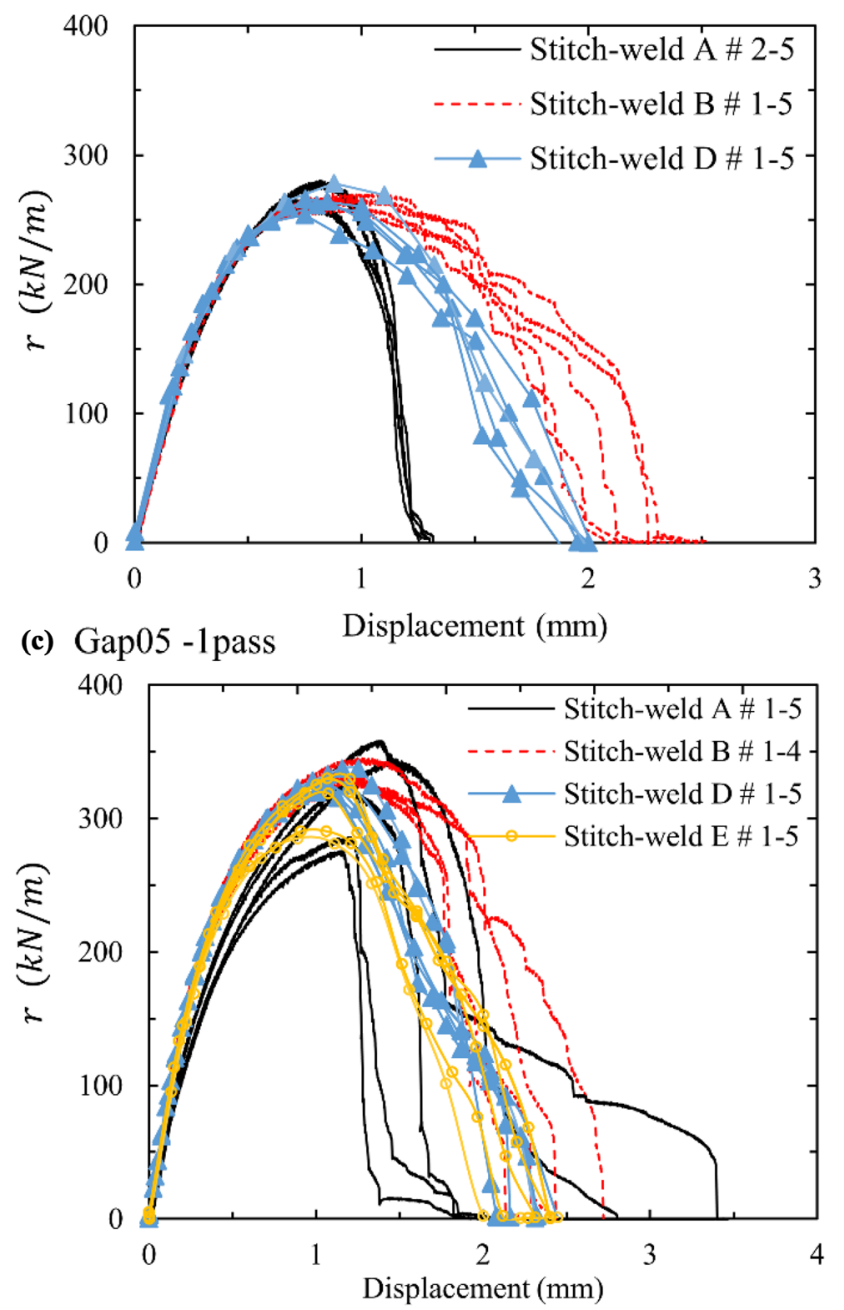

Future work will focus on the influence of the stitch weld shape, part-to-part gap, and second LSR pass on the fatigue behavior of laser welded AA5052-H36 SLJ.

\section{Appendix A shear load to welding length ratio " $r$ "-displacement curves}

(b) Gap00 -2passes

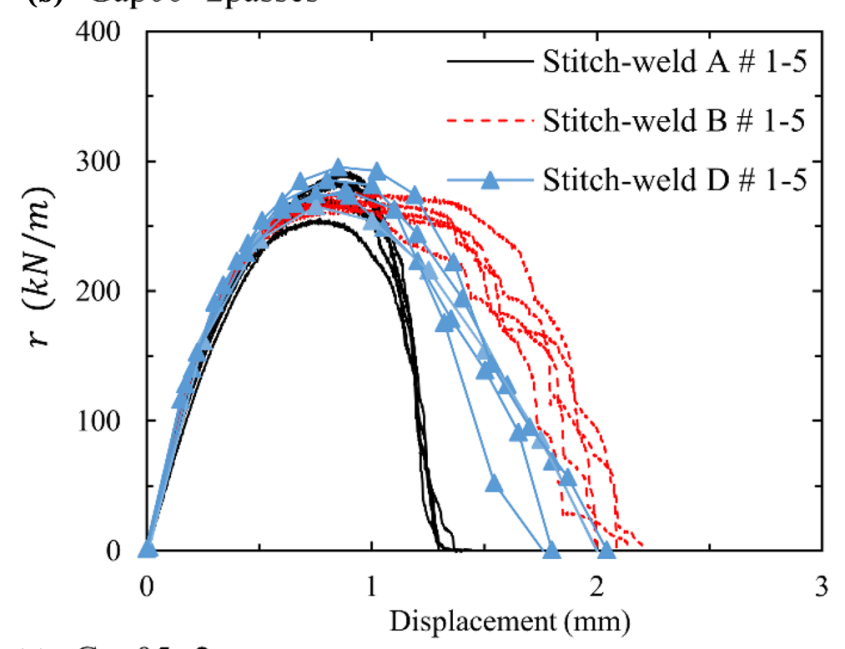

(d) Gap05 -2passes

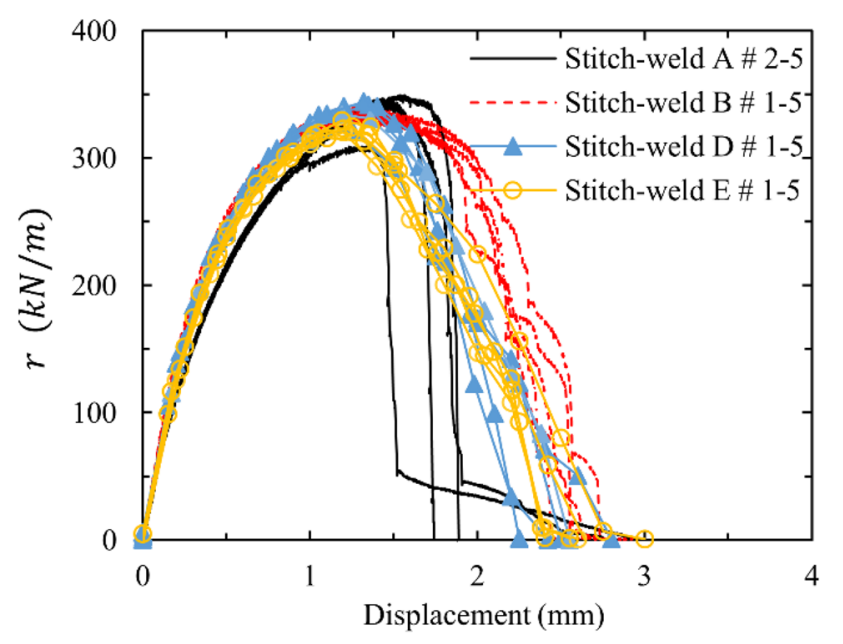

Fig. 15 Shear load to welding length ratio $(\mathrm{kN} / \mathrm{m})$. Displacement $(\mathrm{mm})$ curves for all the tested specimens: a Gap00, 1 pass; b Gap00, 2 passes; c Gap05, 1 pass; d Gap05, 2 passes 
Abbreviations AA: Aluminum alloy; Al: Aluminum; BM: Bare material; CW: Continuous wave; FZ: Fusion zone; Gap00: Gap $=0.0 \mathrm{~mm}$ between sheets during welding (in-contact welded sheets); Gap05: Gap $=0.5 \mathrm{~mm}$ between sheets during laser welding; HAZ: Heat-affected zone; LSR: Laser surface re-melting; NA: Nonapplicable; Nd:YAG: Neodymium-doped yttrium aluminum garnet; PW: Pulse wave; $r(\mathrm{kN} / \mathrm{m})$ : Shear load to stitch weld length; $r_{\max }$ $(\mathrm{kN} / \mathrm{m})$ : Maximum shear load stitch weld length; SEM: Scanning electron microcopy; SLJ: Single lap joint(s); UHSS: Ultrahigh strength steel

Author contribution All authors contributed to the study conception and design. Specimens preparation was performed by Fatemeh Mirakhorli, mechanical tests and analysis were performed by Mohamad Idriss with the collaboration of Ahmed Maslouhi, data validation and general recommendations were provided by Ahmed Maslouhi and Alain DesRochers. The first draft of the manuscript was written by Mohamad Idriss, and all authors commented on previous versions of the manuscript. All authors read and approved the final manuscript.

Funding The authors disclosed receipt of the following financial support for the research, authorship, and/or publication of this article. This work was supported by PRIMA under grant R13-13-008 and by the Natural Science and Engineering Research Council (NSERC) under grant RDCPJ 500450-16.

Availability of data and material (datatransparency) Due to the nature of this research directly related to confidential industrial applications, participants of this study did not agree for their data to be shared publicly, so supporting data is not available.

\section{Declarations}

Ethics approval This article does not contain any studies with human participants or animals performed by any of the authors.

\section{Consent to participate Not applicable.}

Consent for publication The authors confirm that the article is original and that none of the material in the submitted manuscript is currently under consideration for publication elsewhere or has been published previously. All the authors listed on the manuscript have seen and approved the submission of this version of the manuscript and take full responsibility for the manuscript. The authors disclose that there are no prior publications or submissions with any overlapping information. This manuscript has not been and will not be submitted to any other journal while it is under consideration by The International Journal of Advanced Manufacturing Technology.

Conflicts of interest The authors declare no competing interests.

Open Access This article is licensed under a Creative Commons Attribution 4.0 International License, which permits use, sharing, adaptation, distribution and reproduction in any medium or format, as long as you give appropriate credit to the original author(s) and the source, provide a link to the Creative Commons licence, and indicate if changes were made. The images or other third party material in this article are included in the article's Creative Commons licence, unless indicated otherwise in a credit line to the material. If material is not included in the article's Creative Commons licence and your intended use is not permitted by statutory regulation or exceeds the permitted use, you will need to obtain permission directly from the copyright holder. To view a copy of this licence, visit http://creativecommons.org/licenses/by/4.0/.

\section{References}

1. Carle D, Blount G (1999) The suitability of aluminium as an alternative material for car bodies. Mater Des 20(5):267-272. https:// doi.org/10.1016/S0261-3069(99)00003-5

2. Brown KR, Venie MS, Woods RA (1995) The increasing use of aluminum in automotive applications. JOM 47(7):20-23. https:// doi.org/10.1007/BF03221224

3. Baqer YM, Ramesh S, Yusof F, Manladan SM (2018) Challenges and advances in laser welding of dissimilar light alloys: $\mathrm{Al} / \mathrm{Mg}$, $\mathrm{Al} / \mathrm{Ti}$, and $\mathrm{Mg} / \mathrm{Ti}$ alloys. Int J Adv Manuf Technol 95

4. Liu L-M, Wang H-Y, Zhang Z-D (2007) The analysis of laser weld bonding of $\mathrm{Al}$ alloy to $\mathrm{Mg}$ alloy. Scripta Mater 56(6):473-476. https://doi.org/10.1016/j.scriptamat.2006.11.034

5. Cao X, Wallace W, Immarigeon J-P, Poon C (2003) Research and progress in laser welding of wrought aluminum alloys. II. Metallurgical microstructures, defects, and mechanical properties. Mater Manuf Processes 18(1):23-49. https://doi.org/10.1081/ AMP-120017587

6. Cao X, Wallace W, Poon C, Immarigeon J-P (2003) Research and progress in laser welding of wrought aluminum alloys. I. Laser welding processes. Mater Manuf Processes 18(1):1-22. https:// doi.org/10.1081/AMP-120017586

7. Faraji AH, Moradi M, Goodarzi M, Colucci P, Maletta C (2017) An investigation on capability of hybrid Nd:YAG laser-TIG welding technology for AA2198 Al-Li alloy. Opt Lasers Eng 96:1-6. https://doi.org/10.1016/j.optlaseng.2017.04.004

8. Mirakhorli F, Nadeau F, Guillemette GC (2018) Single pass laser cold-wire welding of thick section AA6061-T6 aluminum alloy. J Laser Appl 30(3):032421. https://doi.org/10.2351/1.5040645

9. Pan LK, Wang CC, Hsiao YC, Ho KC (2005) Optimization of Nd:YAG laser welding onto magnesium alloy via Taguchi analysis. Opt Laser Technol 37(1):33-42. https://doi.org/10.1016/j. optlastec.2004.02.007

10. Janasekaran S, Jamaludin M, Muhamad M, Yusof F, Abdul Shukor M (2017) Autogenous double-sided T-joint welding on aluminum alloys using low power fiber laser. Int J Adv Manuf Technol 90

11. Huang L, Hua X, Wu D, Fang L, Cai Y, Ye Y (2018) Effect of magnesium content on keyhole-induced porosity formation and distribution in aluminum alloys laser welding. J Manuf Process 33:43-53. https://doi.org/10.1016/j.jmapro.2018.04.023

12. Beiranvand ZM, Ghaini FM, Moosavy HN, Sheikhi M, Torkamany MJ, Moradi M (2020) The relation between magnesium evaporation and laser absorption and weld penetration in pulsed laser welding of aluminum alloys: Experimental and numerical investigations. Opt Laser Technol 128:106170. https://doi.org/10.1016/j.optlastec.2020. 106170

13. Yuce C, Tutar M, Karpat F, Yavuz N, Tekin G (2017) The effect of process parameters on the microstructure and mechanical performance of fiber laser-welded AA5182 aluminium alloys. Stroj Vestn J Mech Eng 63(9):510-518

14. El-Batahgy A, Kutsuna M (2009) Laser beam welding of AA5052, AA5083, and AA6061 aluminum alloys. Adv Mater Sci Eng 2009:e974182. https://doi.org/10.1155/2009/974182

15. Leong KH, Sabo KR, Sanders PG, Spawr WJ (1997) Laser welding of aluminum alloys. Lasers Tools Manuf II 2993:37-44. https://doi.org/10.1117/12.270039

16. Rapp J, Glumann C, Dausinger F, Hügel H (1995) Laser welding of aluminium lightweight materials: problems, solutions, readiness for application. Opt Quant Electron 27(12):1203-1211 
17. Wang L, Gao M, Zhang C, Zeng X (2016) Effect of beam oscillating pattern on weld characterization of laser welding of AA6061T6 aluminum alloy. Mater Des 108:707-717. https://doi.org/10. 1016/j.matdes.2016.07.053

18. Assuncao E, Williams S (2013) Comparison of continuous wave and pulsed wave laser welding effects. Opt Lasers Eng 51(6):674680. https://doi.org/10.1016/j.optlaseng.2013.01.007

19. Matsunawa A, Kim J-D, Seto N, Mizutani M, Katayama S (1998) Dynamics of keyhole and molten pool in laser welding. J Laser Appl 10(6):247-254. https://doi.org/10.2351/1.521858

20. Matsunawa A, Mizutani M, Katayama S, Seto N (2003) Porosity formation mechanism and its prevention in laser welding. Weld Int 17(6):431-437. https://doi.org/10.1533/wint.2003.3138

21. Huang Y, Shen C, Ji X, Li F, Zhang Y, Hua X (2020) Correlation between gas-dynamic behaviour of a vapour plume and oscillation of keyhole size during laser welding of 5083 Al-alloy. J Mater Process Technol 283:116721. https://doi.org/10.1016/j.jmatprotec. 2020.116721

22. Wang Z, Oliveira JP, Zeng Z, Bu X, Peng B, Shao X (2019) Laser beam oscillating welding of 5A06 aluminum alloys: microstructure, porosity and mechanical properties. Opt Laser Technol 111:58-65. https://doi.org/10.1016/j.optlastec.2018.09.036

23. Oh R, Kim DY, Ceglarek D (2016) The effects of laser welding direction on joint quality for Non-uniform part-to-part gaps. Metals 6(8). https://doi.org/10.3390/met6080184

24. Chen H-C, Pinkerton AJ, Li L, Liu Z, Mistry AT (2011) Gap-free fibre laser welding of $\mathrm{Zn}$-coated steel on $\mathrm{Al}$ alloy for light-weight automotive applications. Mater Des 32(2):495-504. https://doi. org/10.1016/j.matdes.2010.08.034

25. Ma J, Kong F, Carlson B, Kovacevic R (2013) Two-pass laser welding of galvanized high-strength dual-phase steel for a zero-gap lap joint configuration. J Mater Process Technol 213(3):495-507. https://doi.org/10.1016/j.jmatprotec.2012.10.019

26. Jeong YC, Cho YT, Jung YG (2016) Design of stitch welded shape with laser-ARC hybrid welding for ultra-high strength steel. Int J Precis Eng Manuf Green Technol 3(2):193-197. https://doi.org/ 10.1007/s40684-016-0026-2

27. Weman K (2011) Welding processes handbook. Elsevier

28. Matsumoto T, Fukuda N, Kondo Y (1999) Study on prevention of welding defects in high power $\mathrm{CO} 2$ laser materials processing. J Laser Appl 11:258

29. Kanazawa H (1998) Welding performance of high power YAG lasers with aluminium alloys. Weld Int 12(5):341-346

30. Loginova I, Khalil A, Pozdniakov A, Solonin A, Zolotorevskiy V (2017) Effect of pulse laser welding parameters and filler metal on microstructure and mechanical properties of Al-4.7Mg-0.32Mn$0.21 \mathrm{Sc}-0.1 \mathrm{Zr}$ alloy. Metals 7(12). https://doi.org/10.3390/met7120564

31. Geng S, Jiang P, Shao X, Guo L, Gao X (2020) Heat transfer and fluid flow and their effects on the solidification microstructure in full-penetration laser welding of aluminum sheet. J Mater Sci Technol 46:50-63

32. Zhao H, DebRoy T (2003) Macroporosity free aluminum alloy weldments through numerical simulation of keyhole mode laser welding. J Appl Phys 93(12):10089-10096. https://doi.org/10. 1063/1.1573732

33. Kuo TY, Lin HC (2006) Effects of pulse level of Nd-YAG laser on tensile properties and formability of laser weldments in automotive aluminum alloys. Mater Sci Eng A 416(1-2):281-289

Publisher's note Springer Nature remains neutral with regard to jurisdictional claims in published maps and institutional affiliations. 